\title{
Significação da experiência estética no turismo: da sensorialidade ao acolhimento
}

\author{
Olga Araujo Perazzolo* \\ Márcia Maria Capellano dos Santos** \\ Siloe Pereira**** \\ Luciane Todeschini Ferreira****
}

Universidade de Caxias do Sul/Brasil

\begin{abstract}
Resumo: O trabalho tem por suposto a emoção e o afeto como determinantes no valor atribuído à experiência turística, considerando sentimentos de prazer ou desprazer que desta derivam. O sujeito, como um ser biopsicossocial, necessita de eventos emocionalmente significativos e racionalmente provocantes para produzir registros mnêmicos que determinam valores e intervêm na formação de atitudes. Assim, a sensorialidade, de modo geral, e a imagem como meio privilegiado de vivência estética no contexto do turismo, constituem acionadores diferenciados do processo que significa a experiência. Esses aspectos, se fundamentais nas relações de serviços, eles o são ainda mais nas relações cotidianas de hospitalidade e nos processos institucionais de gestão. As sensações ativadas por imagens e outras fontes de apreensão sensoriais evocam representações que fundem passado e presente no processo de (res)significar. Nesse quadro, os sujeitos em relação, na perspectiva turística, podem acolher a emoção do outro, facilitando sua fluência e/ou apoiar a transformação da experiência em novos pensamentos, expectativas, propiciando mudanças e desenvolvimento. A hospitalidade aí se institui como um meio de aceder ao coração da experiência.
\end{abstract}

Palavras-chave: Turismo; Sensorialidade; Acolhimento; Experiência Estética; Fidelização.

\section{Significance of the aesthetic experience in tourism: from sensoriality to reception}

Abstract: This research is oriented to confirm emotions play a pivotal role in the configuration of tourist experience. The self, who sometimes is determined to pleasure and displeasure events, needs of disrupting events so that its cognitive frames may form attitudes. The sense of the world as well as the image as privileged aesthetic instrument, give priority to the significance of experience over other factors. Based on this assumption, we strongly believe the industry of services re-signifies the experience by dint of hospitality to represents traits to evoke the pastime. In parallel with this process, hospitality not only is a good viable tool to retrieve experiences but also to support emotions, expectances to lead into an elaboration of new thoughts (discovery)

Keywords: Tourism, sensorial-view, Hospitality, Aesthetic experience, Loyalty.

* Mestra em Psicologia Clinica e Psicopatologia. Mestre em Educação. Doutoramento em Psicologia: em curso. E-mail: oaperazz@ucs.br

** Doutora em Educação. Mestre em Letras. E-mail: mcsantos@ucs.br

*** Mestra em Psicologia Clinica e Psicopatologia. Mestre em Educação. Doutoramento em Psicologia: em curso. E-mail: spereira@ucs.br

**** Doutora em Letras. Mestre em Comunicação e Semiótica.E-mail: ltferrei@ucs.br. 


\section{Introdução}

Não é recente a constatação de que alguns segmentos científicos de expressiva importância para o estudo do turismo são muitas vezes tangenciados em razão da aparente distância do objeto estudado em relação à area, conforme se constata em estudos como os de Rejowski (2010), dentre outros. $\mathrm{O}$ ainda restrito desenvolvimento do diálogo entre as diferentes ciências seguramente interferem nesse processo.

O tema da emoção, especialmente aquela desencadeada pela via da experiência estética, se insere nesse contexto. Marcada por sediar-se na interface dos domínios psíquico e biológico, a emoção ainda tem sido pouco examinada, apesar de sua óbvia relevância para a compreensão do fenômeno turístico de modo geral, e da valoração do que foi vivido pelo turista, em particular.

A estética, como disciplina que reflete sobre a essência do belo (seu reconhecimento, sua ausência e seu contrário) - qualidade atribuída a elementos naturais, artísticos e a outras produções humanas - tem por pressuposto que ideias e juízos são desdobramentos da experiência emocional gerada pelo prazer estético: heterocósmico, transcendental.

Desde os gregos, o sentido do termo "estética" (aisthésis) remete à ideia de percepção. No entanto, como fenômeno, a percepção é concluída, apenas, com a significação do objeto percebido, significação que, na experiência estética, se dá pela via da mobilização afetiva. É esse o processo que permite ao homem não apenas apreender o mundo externo, tomando-o para si, mas também evadir-se ao extrapolar os limites de seu próprio mundo, construindo novas ideias que transformam o sujeito (percebedor) e o objeto (percebido).

No turismo, o "ver" assume uma importância diferenciada, relativamente a outras situações de vida, e, de certa forma, constitui a síntese de todos os sentidos. Ao deslocar-se intencionalmente para conhecer/reconhecer (em) outro lugar, o turista vive as imagens a que fica exposto como experiências estéticas, portanto inundadas de emoção.

O estudo das emoções foi de interesse por parte de reconhecidos pensadores ao longo do tempo, como Aristóteles, Cícero, Descartes, Hume, James, Freud, entre outros. Nos últimos 20 anos, no entanto, a análise científica da emoção vem progredindo de forma destacada. $\mathrm{Na}$ última década do século XX, o estudo das emoções integrou o conjunto exitoso dos esforços que cunhou a neurociência como área central na chamada década do cérebro e reinseriu-se no centro das atenções da psicologia sobre processos cognitivos.

O pressuposto deste artigo é o de que a emoção constitui um dos afetos determinantes no estabelecimento da valência, positiva ou negativa, de experiências de qualquer ordem. Em outras palavras, diz-se que também na experiência turística (compreendida como movimento que se dá na direção do apreender/conhecer) serão as emoções a base à qual serão aportados os elementos que definem os valores e os tons das marcas mnêmicas que delas derivam, e que definem a hierarquia dos processos facilitadores de aprendizagens.

Tem-se por suposto, ainda, que a experiência é significada primariamente pela emoção e integra o tripé da formação de atitudes humanas, interferindo na forma como os turistas estabelecem laços de fidelização, ou propagam comunicações positivas/negativas sobre o destino visitado. Destaque-se que esse processo, conhecido no domínio das estratégias de marketing como propaganda boca a boca, ainda é considerado como um dos meios mais eficazes de divulgação e desenvolvimento de produtos (Rossi e Slongo, 2012).

Conclusivamente, propõe-se que a emoção - e nela o prazer estético - inaugura a formação de atitudes sobre a "coisa" experienciada, enlaçada pelo fenômeno do acolhimento.

A importância dos aspectos tratados reside na pertinência de focar atenção sobre perspectivas da vida mental que influenciam de forma decisiva no comportamento do turista e repercutem no desenvolvimento do turismo, dos sujeitos e das sociedades. Nesse sentido, reflexões como as que ora são propostas podem subsidiar práticas de gestão/tomadas de decisão desencadeadoras de experiências positivas e de relações geradoras de novos saberes para acolhidos e acolhedores.

\section{A emoção significada}

$\mathrm{Na}$ perspectiva da semiologia do funcionamento psíquico, a emoção constitui-se numa expressão do afeto. A função psíquica da afetividade compreende todas as formas de sentir, incluindo as que são geradas por impulsos agressivos e libidinosos, determinando emoções caracterizadas por sentimentos de prazer ou desprazer (Dalgalarrondo, 2000).

O estado afetivo é lábil por natureza e atua na dinâmica mental estabelecendo as cores que tonalizam todas as demais funções mentais, particularmente as do pensamento e da memória. Disso resulta que as emoções interferem na 
significação das experiências, formando atitudes, envolvendo o valor positivo ou negativo a elas atribuído, determinando a aceitação ou a rejeição de objetos/situações.

Pode-se definir emoção como afetos expressos por componentes psíquicos e somáticos. Embora não devam ser concebidos distintamente, pode-se dizer de modo didático, que os componentes somáticos referem-se às manifestações físicas diversas, de natureza proprioceptiva, exemplificadas pelo arrepio, ou reacionais explícitas, como o choro, os movimentos e expressões corporais. Os componentes psíquicos referem-se às ideias que emergem da emoção e que se associam ao estímulo provocador.

Se adotadas essas premissas na compreensão das vivências humanas no turismo, pode-se supor, por exemplo, que pensamentos sobre a importância de as comunidades manterem suas raízes e tradições tenham sido geradas a partir de emoções provocadas em eventos de exibições culturais, cenarizações, danças, músicas, luzes, dentre as tantas possibilidades de fomento à emergência de sentimentos e afetos a que o turista está sujeito.

A origem acionadora do conjunto de aspectos biopsíquicos que fazem configurar a emoção advém, basicamente, da sensopercepção ou percepção conscientizada, seja a partir de elementos apropriados do ambiente externo, como visões, odores, sabores, seja de elementos internos, como pensamentos e memórias. Assim, além das diferentes formas de captação dos sentidos, também pensamentos e memórias evocam emoções, e essas desencadeiam novos pensamentos e lembranças, caracterizando ciclos que marcam as experiências. Nesse sentido, a evocação de experiências vividas pelo turista faria emergir afetos que tendem a ressignificar a experiência passada e a marcar positivamente ou negativamente a nova lembrança. Memórias da infância, por exemplo, desencadeadas pelo reconhecimento de imagens, objetos, traços culturais, expressões verbais, odores, paisagens, cenários - em situações de turismo - podem remeter a fases da vida, inundando com as emoções similares às do passado a experiência vivida no presente.

Os estudos empíricos e experimentais têm comprovado que respostas fisiológicas a estímulos emocionais podem ser produzidas num circuito que se estende pela córtex cerebral derivando diretamente em efeitos cognitivos, ou seja, intervindo na produção de pensamentos de diferentes formas e níveis de complexidade. A frase de Antonio Damásio (1995), Uma decisão sábia é impossível sem emoção, ratifica o lugar da emoção na totalidade da vida mental.
A teoria do cérebro triplo do neurocientista MacLean (1990) defende que a evolução do cérebro humano se apoia em três camadas: o cérebro reptiliano; o sistema límbico; e o neocortex, cada um responsável por diferentes tipos de emoções, que caracterizam a sequência das épocas evolutivas em que foram constituídos. Essa perspectiva explicita a razão pela qual o cérebro identificaria se determinado evento, fato ou coisa são bons ou ruins antes de saber de forma exata do que se trata, ou antes de produzir um pensamento racional a respeito. Isso indicaria que grande parte do processamento emocional ocorre sem o controle consciente dos sujeitos (Pinto, 1998). Esses estudos, portanto, apoiam o suposto de que as emoções precedem o pensamento e, por decorrência, também a formação de crenças e atitudes.

$\mathrm{Na}$ emoção, a neuroquímica cerebral se estabelece por meio da ativação de regiões específicas da anatomia humana, particularmente envolvendo produção e captação neuronal de substâncias, assim como estruturas cerebrais, como o lobo límbico. Quando caracterizada pelo prazer, a emoção produz a liberação de substâncias endógenas no cérebro que aceleram a captação de neurotransmissores, ampliando as sensações vivenciadas, facilitando os processos de consolidação da memória (Albuquerque e Silva, 2012). Ou seja, um disparo psíquico se efetiva a partir de vivências ou lembranças, (re) marcando com doses de afeto um momento que potencializará de forma significativa o processo de memorização do evento atual.

Numa perspectiva evolucionista, muitas emoções têm função adaptativa, com força de sobrevivência, integrando-se ao repertório da espécie, como emoções desencadeadas pelo brilho e bombardeios produzidos por fogos de artifício, ou por apelos e gritos de ordem coletiva associados a situações que primariamente teriam fomentado a agregação, a coesão grupal, costurados por linhas afetivas, assegurando a sobrevivência dos grupos humanos, tal como proposto por Elias (1994) relativamente à natureza e a importância das relações.

Os espetáculos pirotécnicos apresentados na virada de ano, pela maioria das cidades em todo o mundo, expressam o desejo de emoção e seus efeitos sobre os sujeitos numa dimensão coletiva. Na cidade do Rio de Janeiro (Brasil), por exemplo, até a década de 1980, muitos fogos eram habitualmente lançados à beira mar. Gradativamente, pela intensidade do lançamento, o evento foi atraindo visitantes de bairros próximos e turistas, chegando a reunir um número superior a dois milhões de pessoas, à beira das 
praias da zona sul carioca para assistir ao show, desencadeando explícitas emoções e atitudes de confraternização, sentimentos de apego humano, de otimismo e esperança. Na esteira dos fatos, investimentos públicos foram feitos, de forma a potencializar o nicho turístico, agregando eventos musicais de grande porte, marcando a data como um dos maiores momentos turísticos da cidade. Muitos visitantes voltam anualmente para integrarem-se à festa.

Assim, quanto maior a emoção, maior o impacto sobre a representação mental construída sobre a experiência; maior o sentimento de prazer ou desprazer que a tonaliza; maior a intensidade dos comportamentos que levam à reaproximação ou à evitação de experiências similares futuras; maior a força das lembranças que organizarão o sistema mnêmico, relativamente ao momento vivido (Izquierdo; Bevilaqua; Cammarota, 2006).

$\mathrm{O}$ afeto pode manifestar-se por meio de emoções que expressam diferentes sentimentos, como os de êxtase estético, medo ou pânico, indignação e raiva, indiferença e tédio, afeição e amor, dentre outros. O sujeito pode ser inundado pelo sentimento de otimismo, bem-estar, ou por uma profunda e paradoxal "dor" (uma expressão comportamental típica desse fenômeno é o pranto de alegria ou o sentimento de angústia inexplicável), numa experiência que expressa a intensidade da emoção e/ou atualiza marcos afetivos de sua história pregressa.

Com base no viés psicanalítico, entende-se que a emoção permite trazer à tona cenas imersas no inconsciente, que ainda não foram nominadas e que passam a ser significadas no (re)encontro com uma experiência associada à cena original, ao dar-lhe sentido. Trata-se de um mecanismo similar ao evento traumático que requer um segundo tempo para compreensão, para que possa ser nominado e vivido pela consciência (Freud, 1972). As emoções requerem vias de liberação que derivem em representações por meio das quais o presente e o passado se fundem numa nova experiência profetizadora do futuro.

Ressalte-se que emoções excessivamente perturbadoras podem reprimir a memória, tornando o conteúdo inacessível à consciência. No entanto, as emoções não são esquecidas. Estudos experimentais confirmam os supostos básicos do recalcamento propostos por Freud. Nesses, foi evidenciado que, em situações extremas, a intensidade insuportável da emoção reprime a memória da experiência (Terr, 1991; Holmes, 1990, in Pinto 1998) comprometendo a amplitude e a veracidade das lembranças futuras, gerando confabulações (falsas memórias), ou esquecimentos.
Curiosamente, embora o sujeito não recorde dos fatos, o sujeito identifica ou reconhece o tema como desagradável ou inexplicavelmente perturbador. Esse dado indica que a memória emocional é persistente, não tende a ser reprimida e sim, a dissociar-se do factual quando o quantum de emoção extrapola o limiar da tolerabilidade.

Assim, a emoção e o afeto atuam no processo de significação e na amplificação dos fenômenos que se consolidam sob forma de blocos de memória. A título de exemplo, podem-se citar os blocos mnêmicos que se evidenciam em relatos de turistas sobre como foi a viagem, ou como ocorreu determinado passeio. Esses relatos indicam, via de regra, que a memória se organiza em unidades, alinhando narrativas mentais e linguísticas de modo lógico e coerente, a partir de uma significação prévia que deriva, em grande parte, da emoção que a experiência suscitou.

Também as sínteses verbais que comumente são apresentadas logo ao início de relatos de viagem, como Foi muito bom!, ou Na verdade não gostei, dão força a esse suposto, na medida em que apresentam o afeto predominante como contexto da narrativa, facilitando a compreensão do que está sendo narrado para o ouvinte.

Normalmente, as experiências emocionais negativas são mais intensas do que as positivas, gerando atitudes persistentes e comportamentos de aversão ou rejeição. Essa é uma premissa que encontra respaldo nas práticas cotidianas de recepção do outro, através dos cuidados que evitam desprazeres de um visitante. No âmbito do turismo, isso justifica os cuidados na direção de evitar, tanto quanto possível, que vivências de desprazer sejam experienciadas. Nesse sentido, entende-se que as recomendações técnicas de acolhimento e de segurança da integridade física e moral do turista que, via de regra, integram o planejamento de processos e produtos disponibilizados, visam, não apenas a evitar repercussões jurídicas ou cumprir demandas pessoais de ordem ético-humana, mas minimizar desprazeres e a formação de atitudes negativas. Essa compreensão seria, no mínimo, intuída pelos promotores e receptores turísticos, pois parece integrar o repertório de comportamentos sociais em grande escala. Esses cuidados, se exitosos, potencializariam a fidelização, considerando que o desejo de reviver a experiência positiva está associada ao prazer originalmente vivido (Mazzon e Vera, 2008).

Portanto, a experiência turística quando emocionalmente intensa e positiva é mais facilmente racionalizada por meio da significação, melhor memorizada, e desencadeia o potencial para seu reviver. Eis a base da fidelização, do fenômeno 
que ativa o marketing pessoa - pessoa, de processos que contribuem de maneira diferenciada para o desenvolvimento de empreendimentos e de segmentos econômicos específicos.

As experiências emocionais estão na base da construção de crenças e concepções que tendem a ser duradouras. Nesse sentido, quanto mais intensos e numerosos forem os sentimentos associados a um evento, maior a probabilidade de lealdade à marca a que esse evento está associado. A aquisição de bens, produtos e serviços está relacionada a marcas que nos fazem sentir bem (Cabanac, 1971; Cavalheiro, 2010). As chamadas marcas de sucesso são aquelas sob as quais são guardadas lembranças muito positivas, potencializando sua força, ou o bonding.

Os comportamentos que visam cuidar do visitante, reduzir as chances de vivências de experiências desagradáveis, por sua vez, teriam como efeito evitar a propaganda negativa, do tipo boca a boca, processo que tende a tomar força de propagação superior à propaganda de valência positiva (Laran e Rossi, 2006). Trata-se, portanto, de um processo de formação de atitudes.

A formação de atitudes envolve necessariamente as três dimensões (afeto, pensamento, comportamento). Se qualquer uma dessas destoar, ou assumir uma valência oposta às demais, pode-se dizer que a atitude ainda não foi formada, ou foi desestabilizada. Assim, se uma atitude positiva foi formada em relação a determinado roteiro turístico, deve-se supor que o sujeito sentirá afetos positivos quando evocadas ou emergidas lembranças que se associam ao roteiro conhecido; desenvolverá pensamentos que caracterizarão razões lógicas para suas qualificações; e agirá de forma coerente com a valência positiva predominante, como comentar a terceiros sobre a qualidade do atendimento dos locais visitados, ou refazer o roteiro.

A figura I, a seguir, representa a dinâmica dos elementos que se articulam na formação das atitudes e as derivações em diferentes dimensões turísticas.

\section{Figura 1 - Formação de atitudes e derivações em dimensões turísticas}

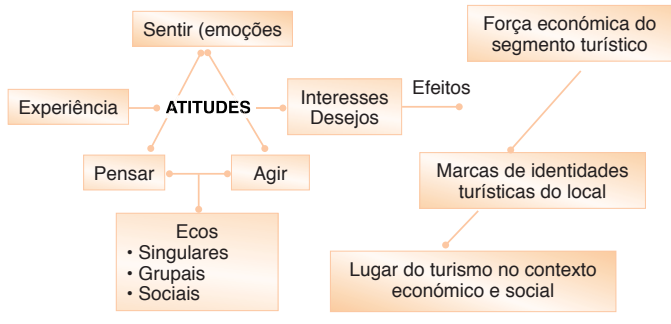

O termo "atitude", portanto, designa um processo por meio do qual os indivíduos sentem, pensam e agem relativamente a determinadas pessoas, situações, objetos (Braguirolli, Rizzon, Bisi, Nicoleto, 2002), constituindo um tripé sustentador dos posicionamentos assumidos ao longo da vida.

Conclusivamente, as emoções que inundam as experiências interferem de forma cabal no processo de sua significação, desencadeando pensamentos e comportamentos formadores de atitudes. A questão parece ser, então, se é possível propiciar que experiências emocionais sejam vivenciadas. É nesse contexto que o acolhimento se insere.

\section{Turismo, emoção e acolhimento}

Se é posto que a emoção constitui um elemento fundamental a ser considerado no processo de planejamento do turismo, proposições acerca das dimensões pragmáticas desse suposto não podem ser feitas com a mesma objetividade. Naturalmente, o controle, ou o manejo de aspectos que determinariam o status das emoções de outra pessoa, constitui, no mínimo, uma tarefa impossível.

De fato, há que considerar a probabilidade de que certas situações, eventos, desencadeiem emoções para um expressivo número de pessoas, como as que envolvem elementos agregadores da espécie, ou a oferta de produtos de valor desejados nas dimensões estética, sensorial e de confortabilidade. Isso viabiliza a elaboração de planos que promovam experiências significativas para turistas, por meio, por exemplo, da observância de aspectos decorativos e arquitetônicos de empreendimentos hoteleiros, na criação de roteiros cujos trajetos permitam ganhos contemplativos, na facilitação de acesso a imagens, sons, sabores.

No entanto, há obvia dificuldade na previsão da forma como cada sujeito vivenciará experiências, considerando suas demandas pessoais, características culturais, contexto de viagem e disposição para as relações.

Inúmeras situações podem desencadear emoções positivas num certo número de sujeitos, mas também desencadear emoções negativas na mesma proporção. Uma apresentação marcada por movimentos sensuais de dançarinos, por exemplo, pode facilitar a emergência de estados emocionais agradáveis e estimulantes para alguns, propiciando a criação de um círculo favorável de pensamentos e ações, mas, de outro lado, facilitar a emergência de estados desa- 
gradáveis para outros. Conflitos conjugais não resolvidos ou processos de envelhecimento ainda não assimilados podem eventualmente induzir à percepção da juventude e da sensualidade de uma dança com as cores negativas do desprazer, ativando a formação de ideias que envolvam, por exemplo, mau gosto, deselegância, embaraço, ou outras.

A emoção está atrelada à visão que cada um tem de si e do mundo, num dado momento, envolvendo concepções acerca de lugares, territórios, culturas, mas também aspectos morais, dificuldades ou potencialidades pessoais, desejos e aversões. Então, como pensar a emoção no contexto do turismo, para além das teorizações que explicitam seu lugar na constituição mental dos sujeitos?

A resposta parece estar no acolhimento, na hospitalidade de uns aos outros.

$\mathrm{O}$ acolhimento concebido como fenômeno que se instaura no espaço que se constitui por meio da relação entre sujeitos (singular, coletivo/institucional) permite a leitura dos processos que promovem a aprendizagem individual/social, e das condições básicas à qualidade da comunicação humana (Perazzolo, Santos e Pereira, 2013). Essa perspectiva atribui às aprendizagens um sentido que extrapola a dimensão cognitiva, abarcando desde unidades afetivas e ideativas até a formação de pensamentos complexos.

Esta proposição está sustentada em supostos teóricos que consideram as relações, manifestadas através de distintas formas, ritmos e tempos de expressão e comunicação, o cerne da vida e do desenvolvimento humano. Essas proposições referem-se, especialmente, às perspectivas sociológicas de Elias (1996), e às psicológicas de Bowlby (1990), relativamente aos elementos de base etológica que corroboram a particular competência da espécie para a vinculação em diferentes níveis e etapas da vida como estratégia biopsicossocial de sobrevivência.

Tendo por base a concepção de acolhimento como processo em que um sujeito acolhe o conteúdo comunicado pelo outro, dá-lhe significação, transforma-o e devolve-o sob forma de novo conteúdo em que, dessa vez, será o outro a transformar. Nesse sentido, acolhimento toma o mesmo

\section{Figura 2 - Dinâmica do processo de significação da experiência turística}

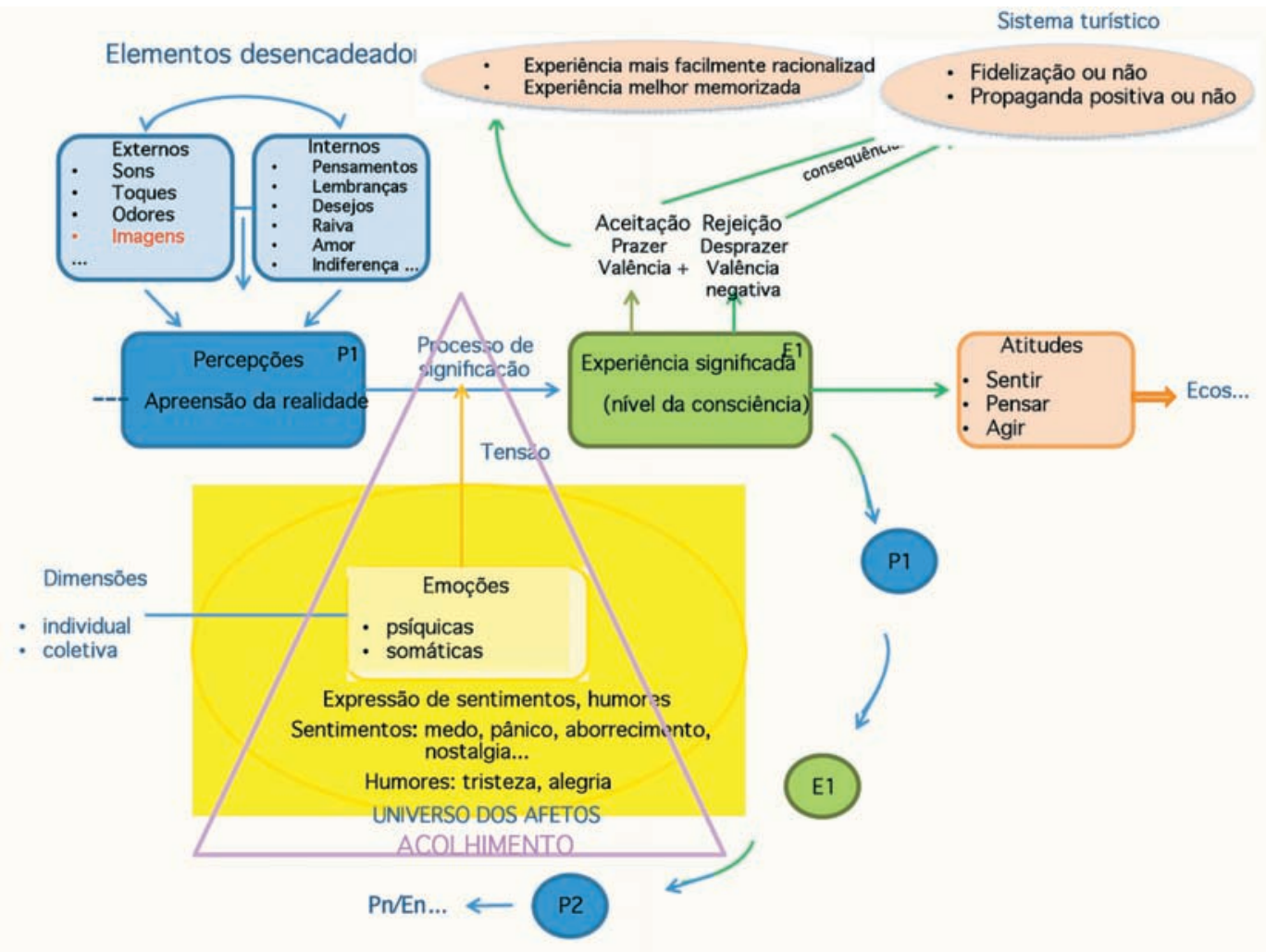


sentido da hospitalidade, particularmente se consideradas as contribuições de Derrida (Dufourmantelle, 2003) no que tange à aceitação do outro, sob pena de sua transformação num igual, destituindo-o de sua condição de sujeito, de outro e de estrangeiro.

Os conteúdos acolhidos podem ser de qualquer ordem, incluindo demandas pessoais, pensamentos, conceitos, ou emoções, e as transformações, que nem sempre ocorrem no mesmo tempo e espaço, geram uma cadeia centrífuga de significações, promotora de aprendizagens para todos os envolvidos. Portanto, todos se tornam acolhidos e acolhedores alternadamente.

Nas práticas do turismo, o acolhimento se dá entre o sujeito primariamente visitante e o primariamente visitado, através das relações pessoa - pessoa, mas também por meio do eco de suas vozes, das estruturas e serviços que disponibiliza.

A contribuição de Selwyn, (2004) relativamente à crença de que o processo de troca integra as práticas de hospitalidade se aproxima da perspectiva antes referida. $\mathrm{O}$ autor adota o sentido de troca, ao invés de relação, mas também concebe trocas de produtos, serviços e materiais simbólicos no âmbito do acolhimento.

$\mathrm{O}$ acolhimento das emoções tem repercussões ainda mais profundas. Envolve a competência humana para perceber, ou intuir, o estado emocional do outro, compreender empaticamente seu significado e constitui-se num continente que oferece apoio, significação, ou apenas o compartilhamento silencioso da experiência. $\mathrm{Na}$ essência, diz-se que o êxito da experiência turística está na forma como as relações foram conduzidas de modo a potencializar o prazer estético, as aprendizagens, através de emergência de emoções positivas. A hospitalidade aí se institui como um meio de aceder ao coração da experiência, de intuir o caminho do prazer do outro, de reconhecer afrontamentos possíveis aos visitantes, de responder à emoção com antecedência, quer no desenho dos roteiros, da oferta de serviços, quer na compreensão empática dos afetos que vierem a ser aflorados. A figura 2, na sequência, representa graficamente esse processo.

Sinteticamente, o gráfico dinamiza o processo em que estímulos externos e internos (elementos desencadeadores) promovem percepções (experiências conscientizadas/significativas) a partir de imagens esteticamente provocantes; de sons visceralmente inquietantes; de lembranças psicologicamente expressivas, etc. As percepções são significadas como agradáveis ou desagradáveis (valência positiva ou negativa) conforme a emoção ativada, determinando tendências de fixação mnêmicas de maior ou menor força, dependendo da intensidade emocional provocada. Cada experiência carrega potencial de ressignificação, particularmente por meio da via relacional, do acolhimento, acionando espirais de crescimento cognitivo-afetivo.

Nesse sentido, o turismo, particularmente na perspectiva receptiva, pode intervir a partir da disponibilização de produtos que - por suposto ofereçam a oportunidade de significação positiva por parte do turista, mas, naturalmente, não poderá assegurar que isso ocorra. Será o acolhimento, ou a relação direta ou indireta entre acolhidos e acolhedores, que permitirá intuir os caminhos pelos quais os desejos de cada um serão concretizados em experiências positivamente valorizadas e transformadoras. Em isso ocorrendo, não apenas a motivação precípua do turismo encontra o destino da realização, como também uma cadeia de eventos favorecerá a fidelização e o fortalecimento do roteiro.

Trata-se, portanto, de uma das formas de enlace unificadora das dimensões intra e sociopsíquico, constituída a partir da experiência paradigmática da demanda que faz o homem se deslocar de seu mundo interno para o externo, na eterna busca de si mesmo.

\section{Referências}

Albuquerque, Fabíola da Silva; Silva, Regina Helena

(2009). "A amígdala e a tênue fronteira entre memória e emoção". Revista de psiquiatria do Rio Grande do Sul vol.31, n.3, pp. 0-0 . Disponível em <http://www.scielo.br/scielo.php?script=sci arttext\&pid=S0101-81082009000400004\&lng=e $n \& n r m=i s o>$. Acesso em 23 mar. 2012.

Dufourmantelle, Anne

2003 Anne Dufourmantelle convida Jacques Derrida a falar da Hospitalidade. São Paulo: Escuta.

Bowlby, John

1990 Apego. 2 ed. São Paulo: Martins Fontes.

Braghirolli, E. M.; Bisi, G. P.; Rizzon, L. A. \& Nicoletto, U.

1997 Psicologia. 9. ed. Petrópolis: Vozes.

Cabanac, Michel

1971 "Physiological role of pleasure". Science, V.173 (1103-7).

Carvalheiro, Andréia C.M.

2010 Experience Marketing: Vender experiências para desenvolver relações entre o consumidor e a marca. Universidade de Coimbra: Faculdade de Economia (Dissertação de Mestrado em Marketing). 
Dalgalarrondo, Paulo

2000 Psicopatologia e Semiologia dos Transtornos Mentais. Porto Alegre: ARTMED.

Damásio, António

1995 O erro de Descartes: emoção, razão e cérebro humano. Fórum da Ciência, Lisboa: Publ. Europa-América.

Elias, Norbert.

1994 O processo civilizador: uma história dos costumes. V. 1. Rio de Janeiro: Jorge Zahar Editor.

Freud, Sigmund (1920)

1972 Além do princípio de prazer. Obras Completas XVI. Rio de Janeiro: Imago.

Izquierdo, Iván; Bevilaqua, Lia R. M.; Cammarota, Martín

2006 "A arte de esquecer". Estudos avançados. São Paulo, v. 20, n. 58 (289-296). Disponível em $<$ http://www.scielo.br/scielo.php?script=sci arttext\&pid=S0103-40142006000300024\&lng =en\&nrm=iso $>$. Acesso em 12 mar. 2012.

Laran, Juliano A.; Rossi, Carlos A. Vargas

2006 "Surpresa e a formação da satisfação do consumidor". RAE- eletrônica. São Paulo, v. 5, n. 1. Disponível em <http://www.scielo. br/scielo.php?script=sci_arttext\&pid=S1676$-56482006000100002 \& \operatorname{lng}=\mathrm{en} \& \mathrm{nrm}=\mathrm{iso}>$. Acesso em 12 mar. 2012.

MacLean, Paul D.

1990 The triune brain in evolution: role in paleocerebral functions. New York: Plenum Press.

Mazzon, José Afonso; Vera, Luis Alberto Noriega 2008 "A opinião dos turistas de negócios sobre a imagem da cidade de São Paulo". Revista Turismo em Análise. São Paulo, v. 19, n. 3 (345-368). Disponível em <http://www. revistasusp.sibi.usp.br/scielo.php? script $=\mathrm{sci}_{\text {}}$ arttext\&pid=S1984-48672008000300002\&lng $=$ pt\&nrm=iso $>$. Acesso em 20 mar. 2012.

Perazzolo, Olga; Santos, Marcia M. Cappellano; Pereira, Siloe

2013 "Dimensión relacional de la acogida". Estudios y perspectivas em turismo. V. 22, pp. 138-152.

Pinto, Amâncio da Costa

1998 "O impacto das emoções na memória: alguns temas em análise". Psicologia, Educação e Cultura, v.2, n, 2 (215-240).

Rejowski, Miriam

2010 "Produção Científica em Turismo: análise de estudos referenciais no exterior e no Brasil". Turismo em análise. v. 21, n. 2 ( $224-246)$.
Rossi, Carlos Alberto Vargas; Slongo, Luiz Antonio

1998 "Pesquisa de satisfação de clientes: o estado-da-arte e proposição de um método brasileiro". Revista de administração contemporânea. Curitiba, v. 2, n. 1 (101-125). Disponível em $<$ http://www.scielo.br/scielo.php? script=sci arttext\&pid $=$ S1415-65551998000100007\&lng= en\&nrm=iso>. Acesso em 10 mar. 2012.

Selwyn, Tom

2004 "Uma antropologia da hospitalidade". In: Lashley, C; Morrison, A. Em busca da hospitalidade : perspectivas para um mundo globalizado. Barueri/SP: Manole.

Recibido:

$02 / 05 / 2013$

Reenviado:

$25 / 06 / 2013$

Aceptado:

$01 / 07 / 2013$

Sometido a evaluación por pares anónimos 